\title{
The prevalence of cardiac autonomic neuropathy in prediabetes: a systematic review
}

\author{
Aikaterini Eleftheriadou ${ }^{1}$. Scott Williams ${ }^{1} \cdot$ Sarah Nevitt $^{2}$ - Emily Brown ${ }^{1} \cdot$ Rebecca Roylance $^{3} \cdot$ John P. H. Wilding ${ }^{4}$. \\ Daniel J. Cuthbertson ${ }^{4}$. Uazman Alam ${ }^{5,6,7}$ (D)
}

Received: 3 March 2020 / Accepted: 10 September 2020 / Published online: 9 November 2020

(C) The Author(s) 2020

\begin{abstract}
Aims/hypothesis Cardiac autonomic neuropathy (CAN) is independently associated with silent myocardial ischaemia, major cardiovascular events, myocardial dysfunction and cardiovascular mortality. Several studies have highlighted the increased prevalence of CAN in prediabetes (impaired glucose tolerance and/or impaired fasting glucose). Considering the exponential rise of prediabetes, we aimed to determine the prevalence of CAN through a systematic literature review.

Methods This systematic review was registered with PROSPERO (CRD42019125447). An electronic literature search was performed using MEDLINE, EMBASE, PubMed, Web of Science, Scopus and Cochrane databases. Published full text, English language articles that provide CAN prevalence data of studies in individuals with prediabetes and aged over 18 years were included. Prevalence data for normal glucose tolerance and diabetes were also extracted from the selected articles, if present. All articles were screened by two independent reviewers using a priori criteria. Methodological quality and risk of bias were evaluated using a critical appraisal tool. Results Database searches found 4500 articles; subsequently, 199 full text articles were screened, 11 of which fulfilled the inclusion criteria (4431 total participants, 1730 people with prediabetes, 1999 people with normal glucose tolerance [NGT] and 702 people with predominantly type 2 diabetes). Six of the selected studies reported definite CAN prevalence data (9-39\%). Only a single large population-based study by Ziegler et al (KORA S4 study, 1332 participants) determined definite CAN based on two or more positive autonomic function tests (AFTs), with a mean prevalence of $9 \%$ in all prediabetes groups (isolated impaired glucose tolerance 5.9\%; isolated impaired fasting glucose $8.1 \%$; impaired fasting glucose plus impaired glucose tolerance $11.4 \%$ ), which was higher than NGT (4.5\%). This study is most likely to provide a reliable population-specific estimate of CAN in prediabetes. There was a higher than expected prevalence of CAN in prediabetes (9-38\%) when compared with normal glucose tolerance (0$18 \%$ ) within the same studies $(n=8)$. There was a wide prevalence of possible CAN based on one positive AFT $(n=5)$. There was heterogeneity between the studies with variations in the definition of CAN, methodology and characteristics of the populations, which likely contributed to the diversity of prevalence estimates. The overall risk of bias was low.

Conclusions/interpretation There is a higher than expected prevalence of CAN in prediabetes. Early detection of CAN in prediabetes through population screening needs careful consideration in view of the excess morbidity and mortality risk associated with this condition.
\end{abstract}

Keywords Cardiac autonomic neuropathy $\cdot$ Lifestyle intervention · Obesity $\cdot$ Prediabetes $\cdot$ Systematic review $\cdot$ The metabolic syndrome

Supplementary Information The online version of this article (https:// doi.org/10.1007/s00125-020-05316-z) contains peer-reviewed but unedited supplementary material, which is available to authorised users.

Uazman Alam

uazman.alam@liverpool.ac.uk

Extended author information available on the last page of the article

\begin{tabular}{ll}
\multicolumn{2}{l}{ Abbreviations } \\
AFT & Autonomic function test \\
CAN & Cardiac autonomic neuropathy \\
HRV & Heart rate variability \\
IFG & Impaired fasting glucose \\
IGT & Impaired glucose tolerance \\
iIFG & Isolated IFG \\
iIGT & Isolated IGT \\
NGT & Normal glucose tolerance
\end{tabular}




\section{Research in context}

\section{What is already known about this subject?}

- $\quad$ Around $7 \%$ of the global population has prediabetes

- Cardiac autonomic impairment may be present in newly diagnosed type 2 diabetes, suggesting an early subclinical phase of cardiac autonomic neuropathy (CAN) that develops in early dysglycaemia

What is the key question?

- What is the prevalence of CAN in prediabetes?

What are the new findings?

- Our systematic review highlights the higher than expected prevalence of CAN in prediabetes

- For population-based studies, CAN prevalence ranged from $0 \%$ to $25 \%$ in prediabetes, which was lower in normal glucose tolerance (0-14\%) for most studies; six studies reported definite CAN prevalence data (9-39\%) and one large population-based study (KORA S4) reported definite CAN prevalence of $9 \%$ in prediabetes compared with $4.5 \%$ in normal glucose tolerance

- We report a wide range of possible CAN prevalence in the selected studies for prediabetes (0-57\%)

How might this impact on clinical practice in the foreseeable future?

- Good glycaemic control and risk factor modification reduces the incidence of CAN

- This highlights the need for population-based screening and risk stratification of people with prediabetes given that CAN may contribute to increased risk of cardiovascular morbidity and mortality

\section{Introduction}

The projected prevalence of prediabetes (people with impaired glucose tolerance [IGT] and/or impaired fasting glucose [IFG]) is similar to type 2 diabetes and both are becoming major global epidemics [1,2]. An estimated $34 \%$ of adults in the USA (equivalent to $\sim 84.1$ million people) had prediabetes in 2015 [3] whereas the IDF projects an increase in prevalence of prediabetes to 471 million globally by 2035 [2]. The prevalence rates of prediabetes have markedly increased in England from $~ 12 \%$ to $\sim 35 \%$ from 2003 to 2011 [4].

Prediabetes is associated with classical microvascular and macrovascular complications suggesting a deleterious environment for microvasculature [5]. The Whitehall study showed that IGT conferred an increased risk of large vessel disease with a doubling of CHD mortality rate [6]. Microalbuminuria is increased in people with IGT compared with healthy individuals [7]. Indeed, there is also a high prevalence of peripheral neuropathy in prediabetes [8]. Asghar et al showed the prevalence of small-fibre neuropathy was $\sim 40 \%$ in prediabetes thus suggesting early nervous system pathology [9]. Abnormalities of autonomic function with impaired sympathovagal balance may coexist with, or even predict subsequent development of, microvascular complications including diabetic neuropathy [10].

Cardiac autonomic neuropathy (CAN) is a serious but underrecognised complication of diabetes, resulting in cardiac denervation and thus increased morbidity and mortality risk [11-14]. The prevalence of CAN in populations with diabetes has been reported to be as high as $90 \%$ [15]. Longitudinal studies in CAN have shown 5 year mortality rates in type 1 and type 2 diabetes of 16-50\%, with a high proportion attributed to cardiac sudden death [16]. The Rochester Diabetic Neuropathy Study showed that in all cases of sudden death, with or without diabetes, there was severe CAN or left ventricular dysfunction [17, 18]. This finding is supported by studies showing that CAN is independently associated with a higher mortality rate, when adjusting for cardiovascular covariates $(1,27,28)$. Moreover, higher mortality rates are observed in individuals with both recent myocardial infarction and abnormal heart rate variability (HRV) $[19,20]$. CAN is associated with major cardiovascular events such as ventricular tachycardia/fibrillation, need for coronary revascularisation and excess cerebrovascular disease [21].

Importantly, cardiac autonomic impairment occurs in the early stages of diabetic metabolic dysfunction with progressive worsening of cardiac autonomic function over time [22, 23]. Risk factors for CAN include prediabetic and diabetic range dysglycaemia, dyslipidaemia, hypertension, elevated BMI and increased waist circumference [24-26]. A number of studies have considered the association between autonomic dysfunction in prediabetes and the metabolic syndrome and have reported an increased prevalence of CAN compared with healthy people [25-29], although this has been contradicted in other published data [30]. 
There have been no systematic reviews undertaken to assess the prevalence of CAN in prediabetes. Our aim was to systematically review the epidemiology of CAN and determine its prevalence in prediabetes in published literature through a systematic literature review.

\section{Methods}

\section{Search strategy}

Following the international standard PRISMA guidelines, the protocol for this review specifying the objectives, inclusion criteria and methods of analysis is registered with PROSPERO (registration ID CRD42019125447). Electronic searches were performed to identify articles reporting the prevalence of CAN in prediabetes, using the following databases: MEDLINE (access via OVID); EMBASE (access via OVID); PubMed; Web of Science; Scopus; and Cochrane databases. As the a priori protocol also included extraction of studies of the metabolic syndrome, this was also included in the initial strategy. A qualified medical librarian (RR) and a second trained researcher (AE) independently conducted database searches. Searches were restricted to English language from inception to June 2019. Combinations of pre-specified search terms were used (Table 1). Results from the databases were merged using EndNote to facilitate the removal of duplicates. Reference lists of studies, review articles and systematic reviews were manually reviewed to identify any additional studies.

\section{Inclusion/exclusion criteria}

A priori inclusion/exclusion criteria were used to select the final article.

Studies were included if they met the following criteria:

(1) case controls, cohorts and observational studies displaying prevalence data for CAN in prediabetes; CAN was defined according to the Toronto Diabetic Neuropathy Consensus Panel as two or more positive tests indicating definite $\mathrm{CAN}$, while possible CAN was defined using a single positive test [14];

(2) included adults $\geq 18$ years old who had prediabetes defined either by the WHO [31, 32] or ADA criteria [33];

(3) were full-text publications.

Studies were excluded if they met the following criteria:

(1) not an original research manuscript;

(2) not a human study;

(3) not conducted in adults ( $\geq 18$ years);

(4) participants did not have prediabetes;
Table 1 Search terms

Prediabetes or the metabolic CAN related terms syndrome related terms

\begin{tabular}{|c|c|}
\hline $\begin{array}{l}\text { 'Pre-diabetes or } \\
\text { prediabetes' }\end{array}$ & 'Cardiac autonomic neuropathy' \\
\hline $\begin{array}{l}\text { 'Impaired glucose } \\
\text { tolerance' }\end{array}$ & $\begin{array}{l}\text { 'Cardiovascular autonomic } \\
\text { dysfunction' }\end{array}$ \\
\hline 'IGT’ & 'Autonomic neuropathy' \\
\hline 'Impaired fasting glucose' & 'Abnormal heart rate variability' \\
\hline 'IFG’ & 'Autonomic Function Tests' \\
\hline 'Metabolic syndrome' & 'Cardiac autonomic function tests', \\
\hline 'MS' & 'Cardiovascular autonomic reflex tests', \\
\hline $\begin{array}{l}\text { 'Insulin resistance } \\
\text { syndrome' }\end{array}$ & 'Borderline autonomic function tests' \\
\hline 'Metabolic syndrome X' & 'Definite CAN' \\
\hline 'Dysmetabolic syndrome' & 'Mild cardiac autonomic neuropathy', \\
\hline \multirow[t]{24}{*}{ 'Syndrome X' } & 'Moderate cardiac autonomic neuropathy' \\
\hline & 'Severe cardiac autonomic neuropathy' \\
\hline & '30:15 ratio’ \\
\hline & 'E/I' \\
\hline & 'E:I' \\
\hline & 'Orthostatic hypotension' \\
\hline & 'Postural hypotension' \\
\hline & 'Neuropathy' \\
\hline & 'Diabetic neuropathy' \\
\hline & 'Valsalva ratio' \\
\hline & 'Heart rate response to deep breathing' \\
\hline & $\begin{array}{l}\text { 'Heart rate response to Valsalva } \\
\text { manoeuvre' }\end{array}$ \\
\hline & 'Resting heart rate variability' \\
\hline & 'Heart rate response to standing' \\
\hline & 'Prolonged QT interval' \\
\hline & 'Sympathetic nervous system' \\
\hline & 'SNS overactivity' \\
\hline & $\begin{array}{l}\text { 'Parasympathetic nervous system } \\
\text { denervation' }\end{array}$ \\
\hline & 'PNS denervation' \\
\hline & 'Vagus nerve denervation' \\
\hline & 'Resting tachycardia' \\
\hline & 'Palpitations' \\
\hline & 'Syncope’ \\
\hline & 'Sudomotor function' \\
\hline
\end{tabular}

(5) did not report prevalence figures of CAN within prediabetes;

(6) were not written in English.

Two authors (AE and SW) independently screened the titles and abstracts from the literature search from all databases mentioned. All eligible articles were selected for full critique. If there was any doubt regarding the eligibility of any given study, the paper was included for critique of the full text. Two 
authors (AE and SW) independently assessed the full text articles, using the inclusion/exclusion criteria. The senior author (UA) decided on exclusion or inclusion, in the event of disagreement. The process of screening and selection for inclusion were recorded using a PRISMA flowchart (Fig. 1).

\section{Data extraction and quality assessment}

Before data extraction and quality assessment, UA screened all articles in order to confirm their eligibility within this study. The data from the final selected articles were extracted independently using a standardised spreadsheet by two authors (AE and SW). Study characteristics, methodology data and results from studies were extracted. Extraction of the studies' first author, study name, year of publication, country, type of study and setting was completed. Subsequently, detailed study characteristics, clinical and demographics data were extracted (e.g. sample size and population data, age/sex, definition of prediabetes, definition and diagnostics of CAN, etc). The combined extracted data was reviewed by UA to ensure accuracy of the data extraction.

\section{Controls and comparators}

Controls and comparators included participants with normal glucose tolerance (NGT) or diabetes. These data were extracted if these groups were included in the selected studies; however, lack of either a control group or diabetes group was not an exclusion criterion.

\section{Critical appraisal}

A critical appraisal tool was used on the final studies selected to be reviewed, specifically addressing the external and internal validity of the articles. AE and SW independently evaluated the quality of the studies using the validated tool developed by Munn et al [34]. Nine questions were posed for each article; a score of 0 or 1 was recorded representing a 'yes' or 'no' response, respectively, determining confounding, selection bias, bias related to measurement and data analysis. A total score between 0 and 3 was considered low risk, 4-6 was moderate risk and $\geq 7$ was high risk of bias, as defined by the authors of the critical appraisal tool. Any discrepancies in the risk of bias were put forward to the senior author (UA) for a final decision.

\section{Definition of CAN and analysis of subgroups}

Definite CAN is defined as two or more positive cardiac autonomic tests as per the definitions of the Toronto Diabetic Neuropathy Expert Group [14]. An a priori decision was made to undertake subgroup analysis of definite CAN vs possible CAN. Methodological variables that may have affected the prevalence in any specific study were extracted (e.g. ethnicity, sex, BMI, age and assessment of autonomic neuropathy).

\section{Data analysis}

All final selected articles were included in the systematic review. Clinical heterogeneity of the studies was assessed by comparing study designs and participant characteristics. Statistical heterogeneity was assessed using the $I^{2}$ statistic [35]. If clinical or statistical heterogeneity was deemed to be too high (e.g. $I^{2}>90 \%$ ) to provide a reliable or useful pooled prevalence estimate, meta-analysis may have been conducted using the generic inverse variance method and conducted with random-effects due to anticipated clinical heterogeneity. However, the heterogeneity was considered clinically high (but $<90 \%$ ), therefore a formal meta-analysis was not conducted. Individual study results are presented in tabular format without the summary pooled prevalence estimate and included in the electronic supplementary material (ESM), and results are described narratively. Prevalence data expressed as a proportion of people with CAN were extracted or calculated from the data available in the studies. A funnel plot was created to show possible bias within the prevalence results (ESM Fig. 1).

All analyses and figure production, including the forest plots, were undertaken using Review Manager 5.4 (Cochrane Collaboration, York, UK). Data in the tables are expressed as mean $( \pm \mathrm{SD}$ or range when applicable).

\section{Results}

\section{Search results}

After the removal of duplicates a total of 4500 articles were generated from the electronic database and manual reference searches. A PRISMA flowchart was completed displaying the article exclusions at each stage of screening (Fig. 1). The titles and abstracts $(n=4500)$ were screened using the inclusion/ exclusion criteria, excluding 4301 articles. Analysis of 199 full texts was performed, 11 of which fulfilled the inclusion criteria, and data were extracted (Tables 2, 3 and 4).

\section{Study characteristics}

Summary of studies The majority of studies were carried out in European populations $(n=7)$ [25, 36-41]; other locations were China $(n=1)$ [42], Brazil $(n=1)$ [43], USA $(n=1)$ [44] and Australia $(n=1)$ [45]. The studies sample sizes ranged from 52 to 1638 participants [25, 36-47]. All studies included tests of cardiac autonomic function. Only two small studies (total participants $n=150$ ) of CAN prevalence in the metabolic syndrome met the inclusion criteria. As their inclusion may 
Fig. 1 PRISMA flowchart demonstrating the article screening process

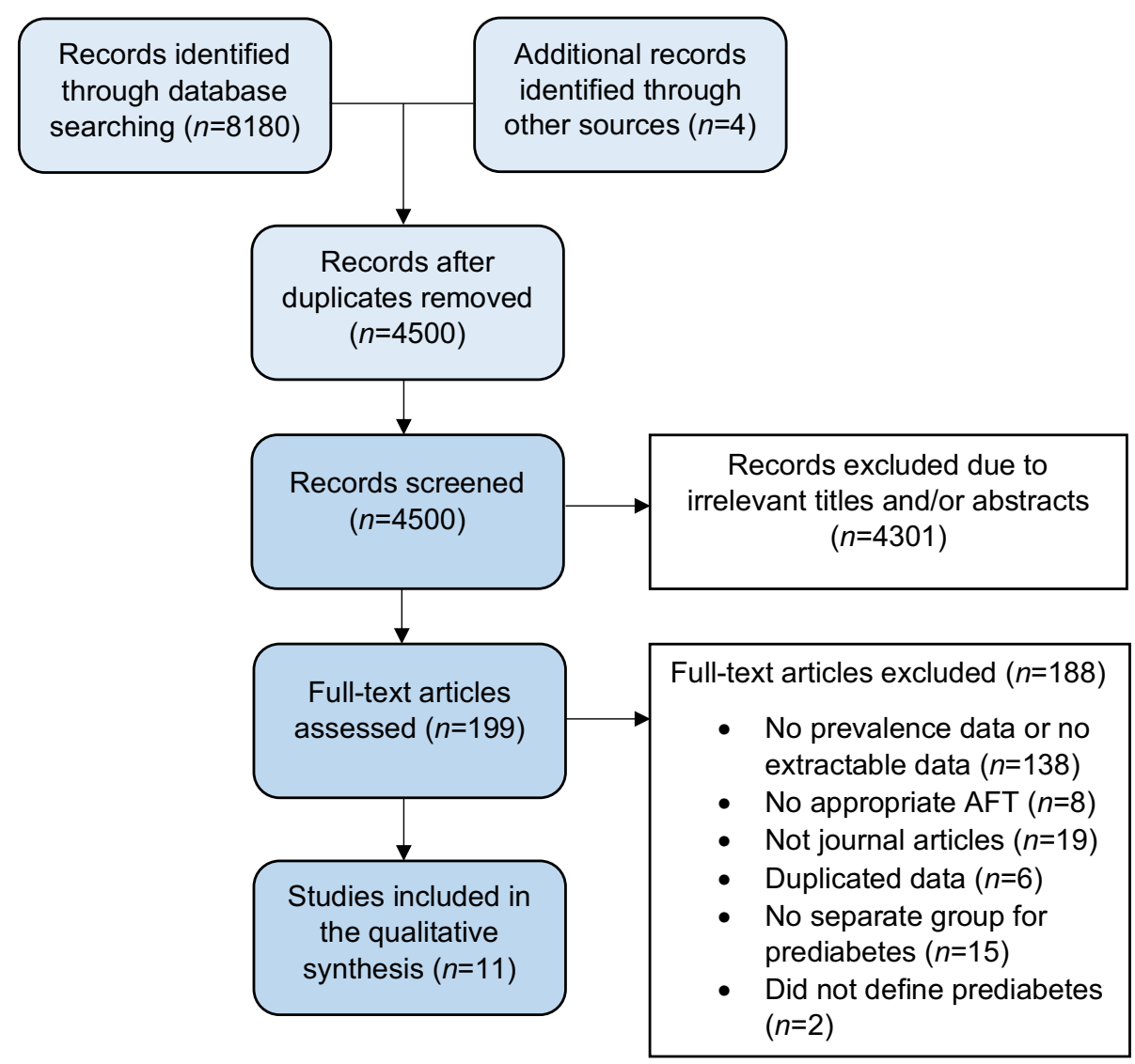

have provided an unrepresentative estimate due to the paucity of data, these results have been included in the ESM (ESM Table 1 and 2) only and will not be considered any further in the main manuscript.

Study design and participants Eight studies were cross sectional $[25,36,37,39,41-44]$, two were cohort studies [38, 40] and one was a prospective observational study [45]. CAN prevalence data were presented for a total of 1730 participants with prediabetes, 1999 participants with NGT and 702 participants with predominantly type 2 diabetes. The mean age of participants in the studies varied from 39 years to 65 years [25, 36-45]. In general, there was similar recruitment of participants based on sex. Five studies defined CAN as one abnormal autonomic function test (AFT) [38-40, 42, 44], whereas six studies required two or more abnormal tests [25, 36, 37, 41, 43, 45]. Eight studies did not report the precise method of participant recruitment [36-39, 41, 43-45] and none of the studies included sample size calculation. CVD characteristics of the recruited participants varied between the selected studies. Five studies excluded participants suffering from ischaemic heart disease, [25, 41, 43-45] five studies included participants with ischaemic heart disease [36-39, 42] and one study did not specify [40].

CAN prevalence was reported for NGT groups in eight studies [25, 36, 39-44] and for diabetes groups in ten studies [25, 36, 37, 40-45].

\section{Prevalence of CAN in prediabetes}

Data from the 11 final selected articles was used to investigate the prevalence of CAN in prediabetes. Six articles presented definite CAN prevalence data $(\geq 2$ abnormal AFTs; 890 participants, prevalence range 9-38.5\%) [25, 36, 37, 41, 43, 45] while five articles presented possible CAN prevalence data (840 participants, prevalence range $0-57 \%$ ) [38-40, 42, 44] in people with prediabetes. When reviewing studies based on the recruitment method (population/primary care-based vs hospital based), prevalence of definite CAN in population-based studies of prediabetes was only undertaken in a single study and was 9\% [25]. The prevalence of definite and possible CAN in larger population-based studies ranged between 9\% $(n=559)$ [25] and 17\% ( $n=412)$ [42] (ESM Fig. 2).

The majority of the studies reported a prevalence of between $20 \%$ and $40 \%(n=3)$ [38, 39, 44] for possible CAN. Larger population-based studies showed higher prevalence of definite and possible CAN in prediabetes compared with NGT. The study of Ziegler et al [25] was the only large sized population-based study $(n=1332)$ detailing definite CAN prevalence, which was $9 \%$ in prediabetes and $4.5 \%$ in NGT. Dimova et al (2017) [36] (478 participants) utilised two AFTs for a positive test and reported a prevalence of $19.8 \%$ in prediabetes and $12.3 \%$ in NGT. Similarly, Wu et al [42] $(n=$ 
Table 2 Participant demographic characteristics information from all final selected articles

\begin{tabular}{|c|c|c|c|c|c|c|c|c|}
\hline Study & Country & $\begin{array}{l}\text { Primary care or } \\
\text { hospital based }\end{array}$ & Sample size & Study group & $\begin{array}{l}\text { Group } \\
\text { size }\end{array}$ & Age, years & $\begin{array}{l}\text { Sex, } n \\
\text { female/ } n \text { male }\end{array}$ & Male, $\%$ \\
\hline \multirow[t]{6}{*}{ Ziegler et al, 2015 [25] } & \multirow[t]{6}{*}{ Germany } & \multirow{6}{*}{$\begin{array}{l}\text { Primary care/ } \\
\text { population based }\end{array}$} & \multirow[t]{6}{*}{1332} & iIFG & 336 & $63(58-68)$ & $128 / 208$ & 62 \\
\hline & & & & iIGT & 72 & $65(62-69)$ & $44 / 28$ & 39 \\
\hline & & & & IFG+IGT & 151 & $65(61-70)$ & $61 / 90$ & 60 \\
\hline & & & & NGT & 565 & $63(58-68)$ & $328 / 237$ & 42 \\
\hline & & & & $\mathrm{kDM}$ & 130 & $65(61-69)$ & $60 / 70$ & 54 \\
\hline & & & & $\mathrm{nDM}$ & 78 & $66(61-71)$ & $33 / 45$ & 58 \\
\hline \multirow[t]{3}{*}{ Dimova et al, 2020 [41] } & \multirow[t]{3}{*}{ Bulgaria } & \multirow[t]{3}{*}{ Primary care/population based } & \multirow[t]{3}{*}{87} & PreDM & 35 & $44.8 \pm 10.2$ & $19 / 16$ & 46 \\
\hline & & & & NGT & 35 & $45.5 \pm 14.1$ & $19 / 16$ & 46 \\
\hline & & & & $\mathrm{nDM}$ & 17 & $48.0 \pm 8.5$ & $10 / 7$ & 41 \\
\hline Laitinen et al, 2011 [38] & Finland & Primary care/population based & 268 & IGT & 268 & $62 \pm 7$ & $177 / 91$ & 34 \\
\hline \multirow[t]{3}{*}{ Wu et al, 2009 [42] } & \multirow[t]{3}{*}{ China } & \multirow[t]{3}{*}{ Primary care/population based } & \multirow[t]{3}{*}{1638} & PreDM & 412 & $49.5 \pm 14.2$ & $218 / 194$ & 47 \\
\hline & & & & NGT & 1069 & $39.4 \pm 14.0$ & $568 / 501$ & 47 \\
\hline & & & & $\mathrm{DM}$ & 157 & $57.7 \pm 12.8$ & $67 / 90$ & 57 \\
\hline \multirow{3}{*}{$\begin{array}{l}\text { Zimmerman } \\
\qquad \text { et al, } 2018[40]^{\mathrm{a}}\end{array}$} & \multirow[t]{3}{*}{ Sweden } & \multirow[t]{3}{*}{ Primary care/population based } & \multirow[t]{3}{*}{119} & IGT & 29 & NA & $9 / 20$ & 69 \\
\hline & & & & NGT & 39 & NA & $18 / 21$ & 54 \\
\hline & & & & (T2)DM & 51 & NA & $15 / 36$ & 71 \\
\hline \multirow[t]{5}{*}{ Dimova et al, 2017 [36] } & \multirow[t]{5}{*}{ Bulgaria } & \multirow[t]{5}{*}{ Primary care and hospital based } & \multirow[t]{5}{*}{478} & PreDM & 227 & NA & NA & NA \\
\hline & & & & IFG & 125 & $51.7 \pm 12.1$ & $71 / 54$ & 43 \\
\hline & & & & IGT & 102 & $49.2 \pm 13.5$ & $71 / 31$ & 30 \\
\hline & & & & NGT & 130 & $46.6 \pm 11.4$ & $82 / 48$ & 37 \\
\hline & & & & (T2)DM & 121 & $54.4 \pm 11.5$ & $54 / 67$ & 55 \\
\hline \multirow[t]{3}{*}{ Balbinot et al, 2012 [43] } & \multirow[t]{3}{*}{ Brazil } & \multirow[t]{3}{*}{ Hospital based } & \multirow[t]{3}{*}{79} & PreDM & 13 & $56.8 \pm 12.6$ & $10 / 3$ & 23 \\
\hline & & & & NGT & 37 & $45.1 \pm 14$ & $21 / 16$ & 43 \\
\hline & & & & (T2)DM & 29 & $59.9 \pm 9.4$ & $10 / 9$ & 31 \\
\hline \multirow[t]{3}{*}{ Dinh et al, 2011 [37] } & \multirow[t]{3}{*}{ Germany } & Hospital based & 145 & IGT & 48 & NA & NA & NA \\
\hline & & & & NGT & $45^{\mathrm{b}}$ & $57 \pm 11$ & NA & NA \\
\hline & & & & (T2)DM & 51 & NA & NA & NA \\
\hline Callaghan et al, 2020 [44] & USA & Hospital based & 184 & Obese PreDM & 56 & $44.7 \pm 11.4$ & $46 / 10$ & 18 \\
\hline & & & & Lean NGT & 46 & $44.1 \pm 12.1$ & $38 / 8$ & 17 \\
\hline & & & & Obese NGT & 33 & $40.2 \pm 10.7$ & $25 / 8$ & 24 \\
\hline & & & & Obese DM & 49 & $48.9 \pm 10.4$ & $34 / 15$ & 31 \\
\hline Putz et al, 2013 [39] & Hungary & Hospital based/primary care & 115 & IGT & 75 & $58.7 \pm 11.1$ & $41 / 34$ & 45 \\
\hline & & & & NGT & 40 & $55.1 \pm 10.0$ & $23 / 17$ & 43 \\
\hline Kamel et al, 2014 [45] & Australia & NA & 52 & IGT & 8 & NA & NA & NA \\
\hline & & & & NGT & $26^{\mathrm{b}}$ & 49 & $13 / 13$ & 50 \\
\hline & & & & $\mathrm{DM}$ & 18 & NA & NA & NA \\
\hline
\end{tabular}

Age data are shown as mean \pm SD or median (range)

${ }^{a}$ Data from the starting point of the cohort study was used; however, the authors presented the starting point data only for the participants that remained in the cohort study until the latest follow-up

${ }^{\mathrm{b}}$ Not included in the total population for this review as no prevalence data available for this population

Prediabetes groups: IFG, IGT, iIFG and iIGT

DM, diabetes mellitus; FPG, fasting plasma glucose; kDM, known diabetes mellitus; NA, information is not available; nDM, new diabetes mellitus; PreDM, prediabetes; (T2)DM, type 2 diabetes mellitus

1638) used one AFT and showed a CAN prevalence of $18 \%$ in prediabetes and $14 \%$ in NGT. Table 4 and ESM Figs. 2a, 2b, 3 and 4 summarise data by displaying the prevalence figures for each study.

\section{Secondary analyses}

In the NGT groups, overall CAN prevalence ranged from $0 \%$ to $18 \%$. Definite CAN prevalence was reported in four studies $(812$ 


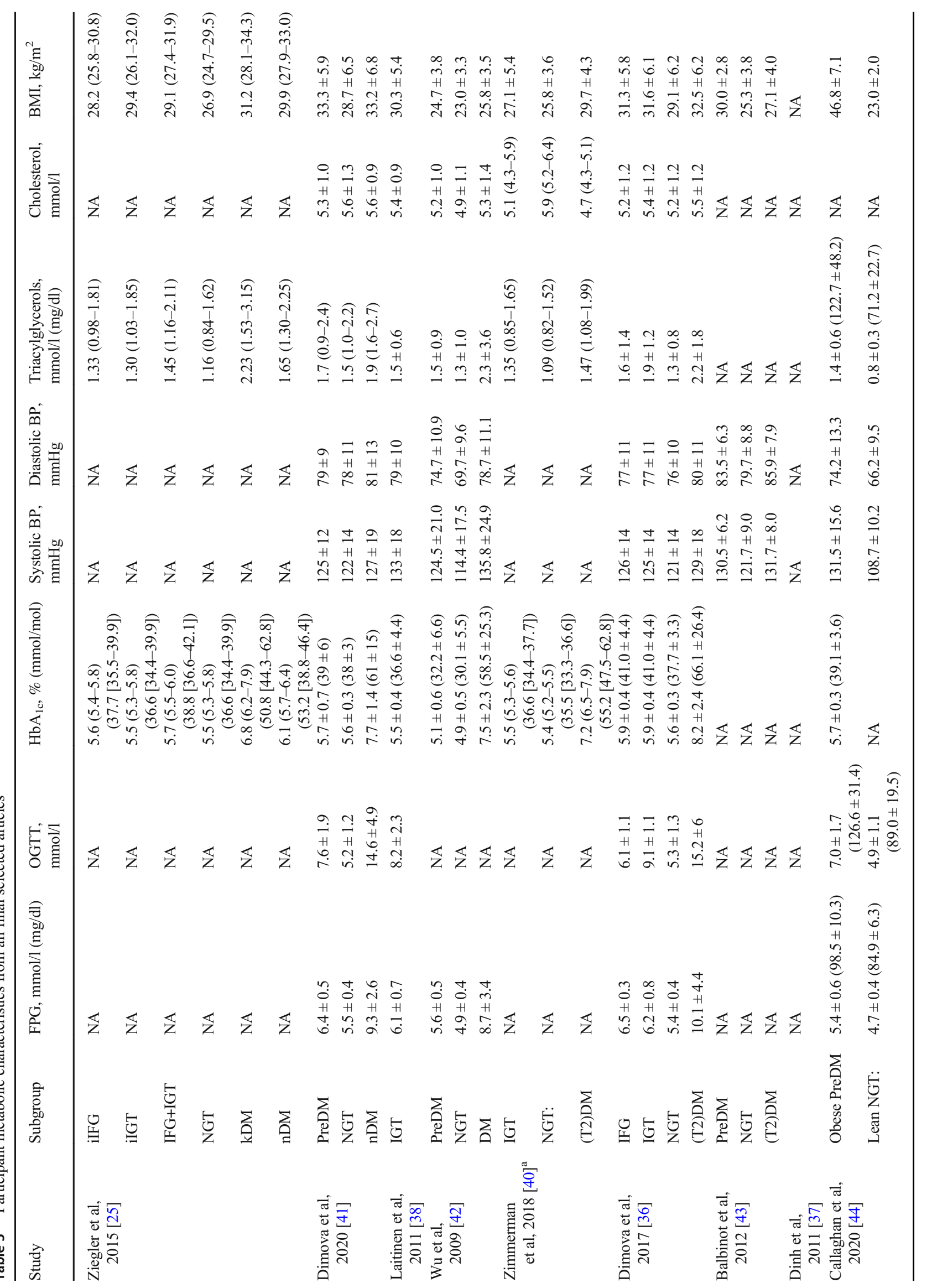




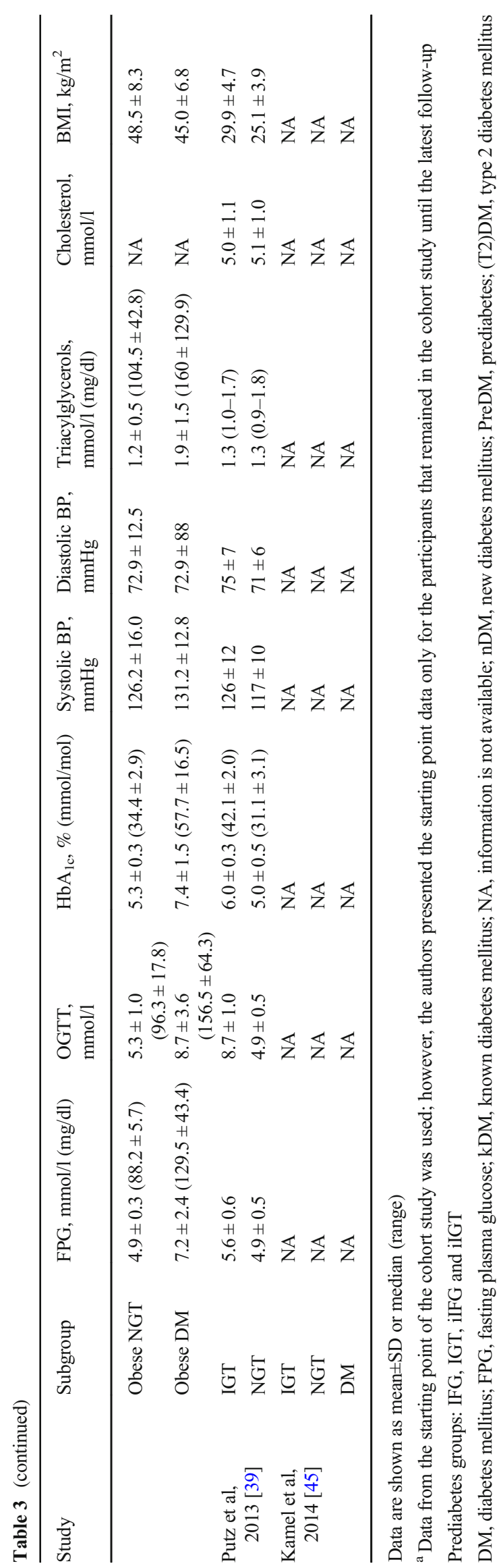




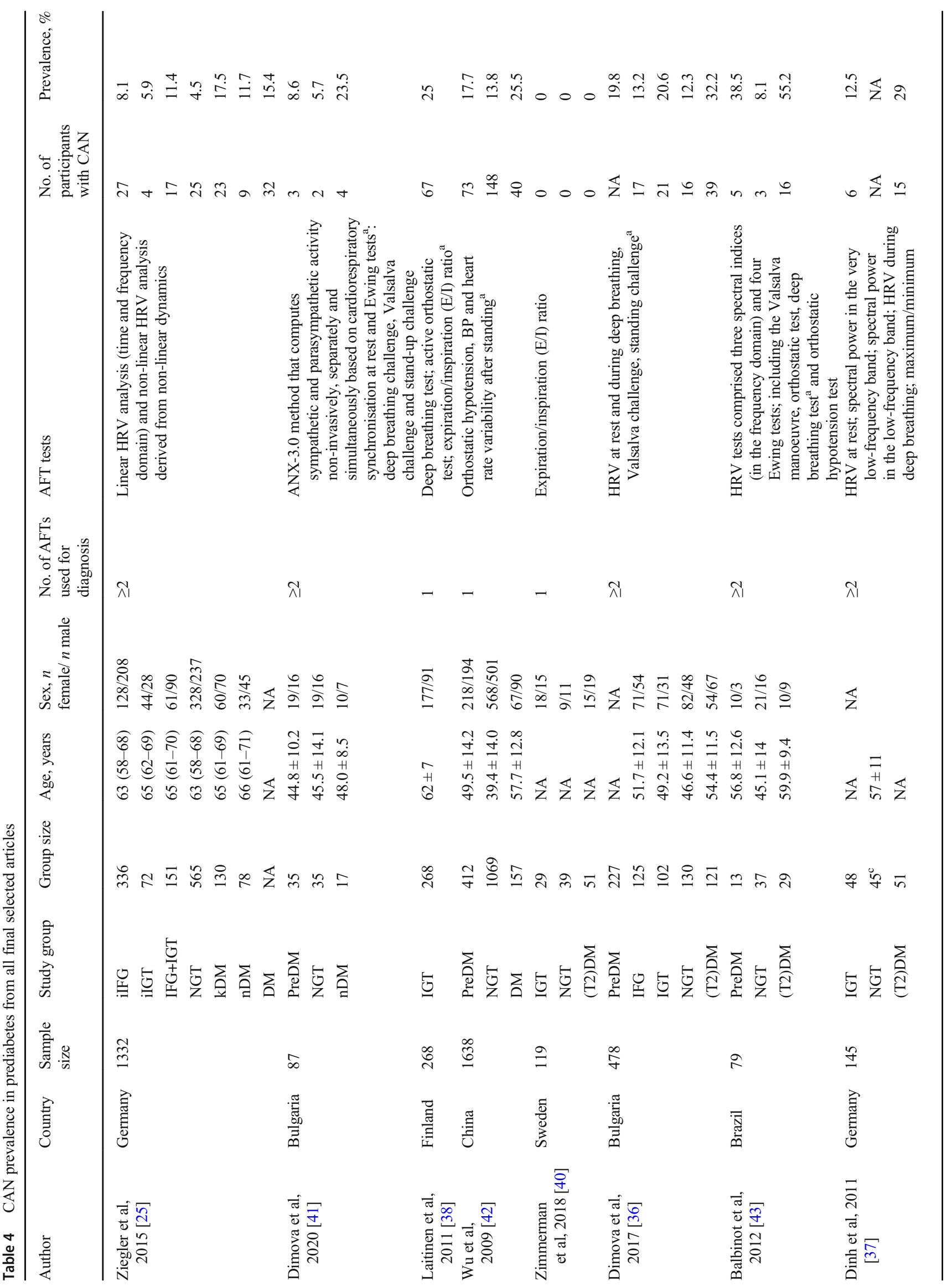




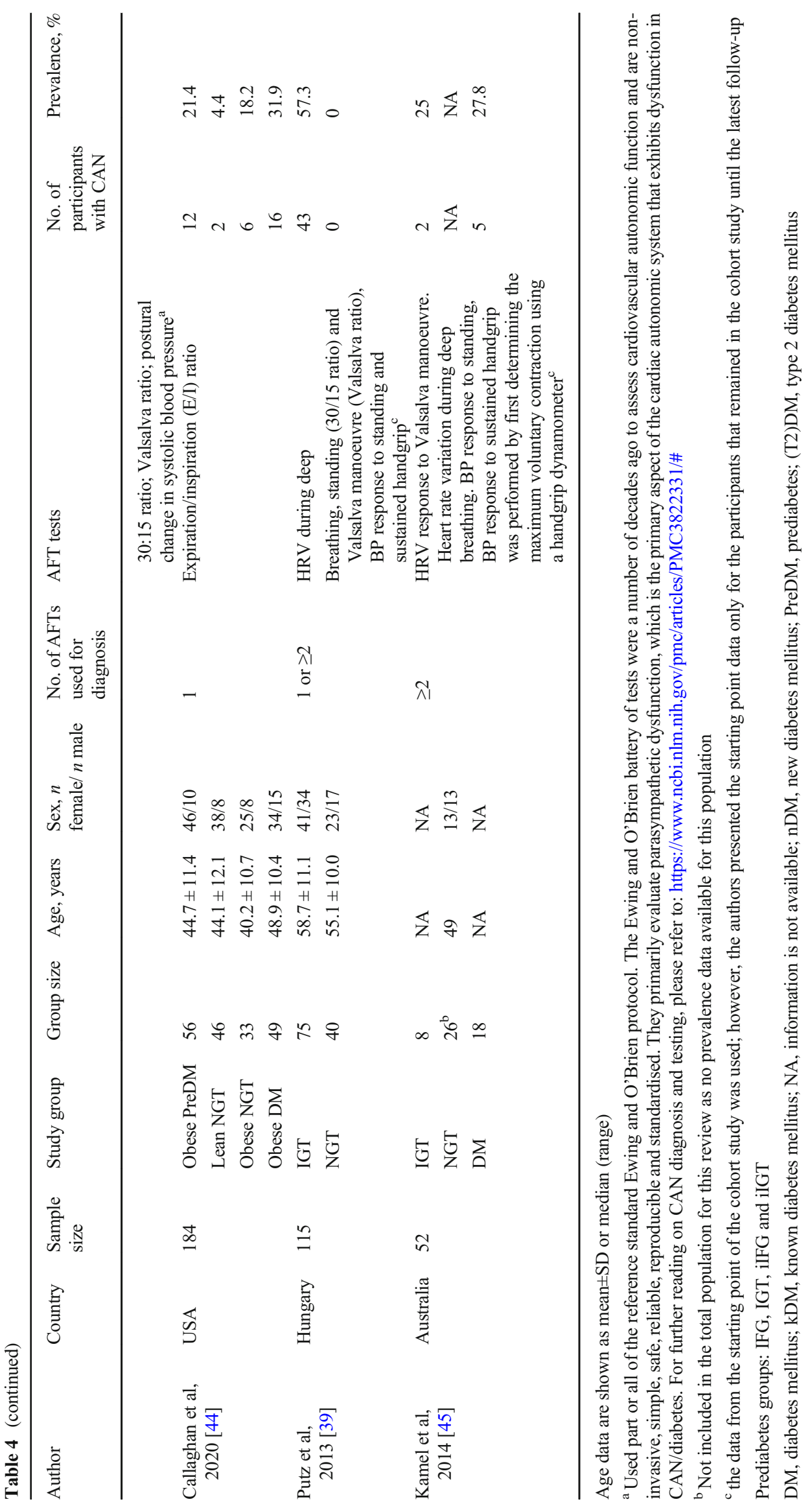


participants, prevalence range $4-18 \%)[25,36,41,43]$. The majority of the studies reported an overall prevalence $<10 \%$ $(n=5)$ [25, 39-41, 43], although in the two adequately sized population-based studies $[25,42]$ the prevalence was $4.5 \%$ and $13.8 \%$ (ESM Fig. 3). Interestingly, Callaghan et al [44] found CAN prevalence in obese NGT to be $18.2 \%$, which approached that in prediabetes $(21.4 \%)$ suggesting that constituents of the metabolic syndrome play an important role in the pathogenesis.

Overall CAN prevalence (definite and possible) in the diabetes groups was more widely dispersed and ranged from $0 \%$ to $56 \%[25,36,37,40-45]$ (diabetes prevalence: $<10 \%$, $n=1$ [40]; $10-20 \%, n=1$ [25]; 20-30\%, $n=4$ [37, 41, 42, 45]; $30-40 \%, n=1$ [36]; $>40 \%, n=1$ [43]) (ESM Fig. 4). Definite CAN prevalence in diabetes was reported in six studies (445 participants) $[25,36,37,41,43,45]$ and ranged from $15.4 \%$ to $55.2 \%$. In population-based studies $(n=4)$ it ranged from $11.7 \%$ to $56.6 \%$ [25, 40-42].

\section{CAN definition and tests}

The definition of CAN varied between the studies. CAN was defined as three abnormal AFTs $(n=1)$ [43], two abnormal $\operatorname{AFTs}(n=5)[25,36,37,41,45]$ or one abnormal AFT $(n=5)$ [38-40, 42, 44]. A single study used gold standard HRV spectral power analysis to define CAN [25].

\section{Different surrogate biomarkers for the criteria of CAN among} the studies All of endpoints used HRV response to physical manoeuvres $(n=11)$, according to Ewing's protocol, including deep breathing HRV $(n=9)$ [36-41, 43-45], Valsalva challenge $\operatorname{HRV}(n=6)[36,37,39,41,43,45]$ and HRV response to standing challenge $(n=8)[36,37,39,41-43$, $45,46]$. Additionally, spectral HRV analyses were also utilised $(n=4)$ [25, 37, 41, 43]. Study CAN definitions are detailed in ESM Table 3.

\section{Risk of bias}

Evaluation of bias and article quality showed all studies had a score suggestive of a low risk of bias. The median (IQR) risk of bias score was low at 1.6 (1.0) (out of 9) (ESM Table 4).

A funnel plot was created which showed no clear evidence of asymmetry, therefore it is unlikely that publication bias is present within this review (ESM Fig. 1).

\section{Discussion}

The primary finding of this systematic review of 11 studies involving 1730 participants with prediabetes [36-39, 42, 43, 45] is the high prevalence of CAN in studies reporting prevalence based on the Toronto criteria. Prevalence of definite CAN was $9 \%$ in the sole population-based study of prediabetes, which determined CAN based on two or more AFTs [25]. The prevalence of definite and possible CAN in adequately sized population-based studies ranged between $9 \%$ and $17.7 \%$ and was greater than populations with NGT reported within the same studies $[25,42]$. Unfortunately, a true estimate of populationlevel prevalence was not feasible due to the heterogeneous nature of the studies. There is a clear need to ascertain a true estimate of definite CAN using reference standard AFTs in a future large primary care-based study, primarily to ascertain levels of comorbidity in a prediabetes population with longitudinal evaluation. The results of this systematic review support the hypothesis that autonomic dysfunction is present in individuals with prediabetes prior to the development of overt type 2 diabetes.

\section{CAN and CVD risk}

CAN prevalence has been extensively investigated in diabetes and is associated with increased morbidity and mortality risk [48-52]. Therefore, the high morbidity and mortality rates that occurs as a result of CAN is of major concern, given the global epidemic of prediabetes. CAN itself is linked to increased prevalence of silent presentation of myocardial ischaemia [52]. An increase in all-cause mortality rates and cardiovascular events was independently associated with resting and mean heart rate in post hoc analyses of the Ongoing Telmisartan Alone and in combination with Ramipril Global Endpoint Trial (ONTARGET) and the Telmisartan Randomised Assessment Study in ACE Intolerant Subjects with Cardiovascular Disease (TRANSCEND) trial [53]. Both were large trials in medically optimised patients with stable CVD. Importantly, for an increase of 10 beats/min in resting and mean heart rate, there was a significant increase in risk of major vascular events, cardiovascular death, congestive heart failure and all-cause mortality rates [53]. Resting heart rate and blunted HRV are two measures of cardiac autonomic nervous system imbalance, the influence of which were evaluated in the Framingham Heart Study offspring cohort [54]. These measures, in addition to demographic (age and sex) and cardiovascular risk factors (smoking) were significant predictors in the development of CVD, diabetes and premature death (within 12 years) [54]. Given that myocardial blood flow is regulated by cardiac adrenergic signalling and coronary blood flow increases in response to sympathetic stimulation [55], it is of little surprise that CAN results in impaired coronary blood flow $[56,57]$. Despite the significant excess CVD events and mortality risk, CAN screening is not routinely performed as a part of annual diabetes or prediabetes screening.

\section{Pathophysiology of CAN in prediabetes}

The pathophysiology of CAN relates to multifactorial changes that occur in prediabetes and lead to oxidative stress, mitochondrial dysfunction with subsequent neuronal damage and dysfunction of autonomic ganglion synaptic transmission 
[58-60]. Dysglycaemia in prediabetes is a common route to multiple pathophysiological pathways that lead to autonomic neuropathy. Similarly, the findings of Rasic-Milutinovic et al [46] support the notion that continuously elevated glucose level, as a component of the metabolic syndrome, correlates with spectral HRV indices [46]; other supporting data have been published [29]. Interestingly, Rasic-Milutinovic et al [46] also reported disturbed sympathovagal balance with dominant parasympathetic dysfunction in individuals with the metabolic syndrome and type 2 diabetes in keeping with the natural history of CAN. There is an association between BMI, plasma triacylglycerols/remnant lipoproteins and the risk for diabetic peripheral neuropathy even in type 1 diabetes [61]. In a post hoc analysis of participants $(n=427)$ with mild to moderate diabetic neuropathy, elevated triacylglycerols correlated with myelinated fibre density loss independent of disease duration, age, diabetes control or other variables [62]. It has also been suggested that cholesterol-lowering treatments (statins and ezetimibe) [63] and triacylglycerol-lowering treatments (fibrates) [63] may reduce the progression and severity of diabetic peripheral neuropathy. Well-planned randomised trials to evaluate the impact of intensive plasma lipid normalisation on diabetic peripheral neuropathyand CAN are required. Please see Williams et al [23] for a thorough discussion on the multifactorial pathophysiology of CAN in obesity, prediabetes and the metabolic syndrome (including a detailed figure on the pathophysiology). Looking beyond the modest degree of hyperglycaemia, additionally obesity, dyslipidaemia, inflammation and hypertension play a pivotal role in CAN development.

\section{Prediabetes, IFG or IGT in CAN development}

Prediabetes is defined using IFG, IGT or $\mathrm{HbA}_{1 \mathrm{c}}$ and three of the studies in this review showed that these components may have a different effect on the development of CAN. Watkins et al [64] established that the association between autonomic function and IFG was primarily mediated through hypertension, obesity and ageing, suggesting the possibility that elevated fasting glucose has a lesser effect on the impairment of autonomic control. Dimova et al [36] highlighted the role of postprandial hyperglycaemia, with $120 \mathrm{~min}$ glucose correlating to sympathetic activity [36]. The MONICA/KORA study investigated the prevalence of CAN in isolated IFG (iIFG), isolated IGT (iIGT) and combined IFG and IGT (IFG+IGT), showing differential prevalence within these groups (iIFG $8.1 \%$, iIGT 5.9\%, IFG+ IGT $11.4 \%$ ) [25]. This trend is consistent with the suggestion made by Watkins et al [64] that each of these components may independently contribute to CAN, although the prevalence rates in all prediabetes groups were the lowest of the included studies. Ziegler et al [25] suggest that the individuals with IFG+IGT are at the highest risk of autonomic dysfunction compared with iIGF and iIGT. In a meta-analysis, annualised incidence rates of diabetes for individuals with iIGT (4-6\%) and iIFG (6-9\%) were lower than those in individuals with IFG+IGT (15-19\%) [65]. This may suggest that IIFG and IIGT, albeit they are insulinresistant states, differ in their pathophysiology and site of insulin resistance. People with iIFG predominantly have hepatic insulin resistance, whereas individuals with iIGT have moderate to severe muscle insulin resistance [66]. Insulin resistance results in oxidative stress through mitochondrial dysfunction, which is characterised by smaller mitochondrial size and decreased mitochondrial DNA content [67]. Indeed, glucose-mediated oxidative stress contributes to the development and progression of diabetic neuropathy by inducing an imbalance in mitochondrial biogenesis and fission [68]. There is also a higher prevalence of obstructive sleep apnoea in prediabetes and the metabolic syndrome [69]. Several studies in individuals with obstructive sleep apnoea have shown autonomic nervous system alterations, in particular sympathetic overactivity, both acutely during apnoea events and chronically during the daytime [70].

\section{Early detection of CAN}

The early detection of CAN is crucial in its treatment due to it being readily reversible in people with prediabetes [71]. Several studies have reported that good glycaemic control reduces the incidence of CAN and slows its progression, particularly in the early stages but not when advanced autonomic abnormalities appear [11, 58, 72]. Additionally, there is a positive correlation between the duration of diabetes and CAN [14]. Consequently, it is important to underline the high prevalence of CAN during the early stages of glycaemic dysregulation where CAN, prediabetes and the metabolic syndrome are all reversible. Treating the modifiable risk factors for prediabetes and the metabolic syndrome that also modulate autonomic dysfunction presents an opportunity for the reversal of CAN. There remains a paucity of data in this cohort (prediabetes/the metabolic syndrome); however, lifestyle intervention in people with IFG or IGT resulted in a reduction in heart rate and increase in HRV over 4 years, according to the Diabetes Prevention Programme [71]. Therefore, lifestyle intervention is an effective means of managing early CAN and should be utilised as a part of a multifactorial therapeutic strategy.

\section{Limitations and future work}

There were a number of causes of high heterogeneity, including participant populations and ethnicity, therefore limiting the study to a systematic review. Ethnicity is a predictor for the development of CAN, thus comparing prevalence rates of CAN between different ethnicities is problematic [45]; however, a recent study found no differences between South Asians and white Europeans in the prevalence of CAN [73]. The final number of articles included in this review was small, which prevented detailed secondary analyses. None of the studies included displayed an appropriate sample size 
calculation and some had low numbers of participants. Several studies were hospital based and also recruited participants from a single centre while others did not detail recruitment strategies. This study was limited to English language and published data which may introduce bias. Additionally, there was heterogeneity in relation to the method of diagnosis of prediabetes (and new-onset diabetes/NGT), as both $\mathrm{HbA}_{1 \mathrm{c}}$ and glucose tolerance were included as methods for diagnosis. Unfortunately, a detailed analysis of the metabolic syndrome was not possible due to limited numbers of studies. Directions for future research include establishing whether subclinical CAN progresses to overt CAN and examining the relationship of CAN to other microvascular complications in a dedicated prevalence study in the general population incorporating a prospective longitudinal cohort. In addition, with the recent success of the Diabetes Remission Clinical Trial (DiRECT) in achieving diabetes remission through a very-low-energy diet [74], a further interrogation of this effect on the natural history of CAN in a prediabetes population is warranted.

\section{Conclusion}

There is a higher than expected prevalence of CAN in prediabetes. Early detection of CAN through population-level screening needs careful consideration in view of the excess morbidity and mortality risk associated with this condition. However, there is still a need for an adequately sized international multicentre population-based study to ascertain the prevalence of definite CAN with longitudinal follow-up for 'hard' cardiovascular outcomes in prediabetes.

Acknowledgements We would like to acknowledge staff at the Edge Hill University Library, Clinical Sciences Centre, Aintree University Hospital for their support.

Data availability The datasets generated during and/or analysed during the current study are available from the corresponding author on reasonable request. All data are available from primary publication sources.

Funding This research received no specific grant from any funding agency in the public, commercial or not-for-profit sectors.

Authors' relationships and activities The authors declare that there are no relationships or activities that might bias, or be perceived to bias, their work.

Contribution statement All authors contributed to the conception, conduct of the study and the writing of the manuscript. AE analysed the data, wrote the first version of the manuscript, and edited the manuscript. SW was responsible for the data collection, reviewed the manuscript and contributed to the discussion. SN conceived the study, contributed to the study design, and facilitated and conducted the statistical analyses. EB conceived the study and helped to facilitate pre-screening of abstracts, data collection and template design. RR conceived the study and undertook databases searches. JPHW conceived the study, contributed to the manuscript and reviewed the manuscript. DJC conceived the study, contributed to the manuscript and reviewed the manuscript. UA conceived the study, participated in data collection, wrote the manuscript and contributed to the discussion. All authors approved the final version of the manuscript to be published. UA is the guarantor of this work and, as such, had full access to all the data in the study and takes responsibility for the integrity of the data and the accuracy of the data analysis.

Open Access This article is licensed under a Creative Commons Attribution 4.0 International License, which permits use, sharing, adaptation, distribution and reproduction in any medium or format, as long as you give appropriate credit to the original author(s) and the source, provide a link to the Creative Commons licence, and indicate if changes were made. The images or other third party material in this article are included in the article's Creative Commons licence, unless indicated otherwise in a credit line to the material. If material is not included in the article's Creative Commons licence and your intended use is not permitted by statutory regulation or exceeds the permitted use, you will need to obtain permission directly from the copyright holder. To view a copy of this licence, visit http://creativecommons.org/licenses/by/4.0/.

\section{References}

1. Ogurtsova K, Fernandes JDD, Cavan D, Makaroff LE, Grp IA (2016) Global estimates of undiagnosed diabetes in adults for the 2015 IDF diabetes atlas: a revision of the methodology. Diabetes 65:A405-A405

2. IDF Diabetes Atlas Group (2015) Update of mortality attributable to diabetes for the IDF diabetes atlas: estimates for the year 2013. Diabetes Res Clin Pract 109:461-465. https://doi.org/10.1016/j. diabres.2015.05.037

3. O'Connell JM, Manson SM (2019) Understanding the economic costs of diabetes and prediabetes and what we may learn about reducing the health and economic burden of these conditions. Diabetes Care 42:1609-1611. https://doi.org/10.2337/dci19-0017

4. Mainous AG, Tanner RJ, Baker R, Zayas CE, Harle CA (2014) Prevalence of prediabetes in England from 2003 to 2011: population-based, cross-sectional study. BMJ Open 4:e005002. https:// doi.org/10.1136/bmjopen-2014-005002

5. Brannick B, Wynn A, Dagogo-Jack S (2016) Prediabetes as a toxic environment for the initiation of microvascular and macrovascular complications. Exp Biol Med (Maywood) 241:1323-1331. https:// doi.org/10.1177/1535370216654227

6. Fuller JH, Shipley MJ, Rose G, Jarrett RJ, Keen H (1980) Coronary-heart-disease risk and impaired glucose tolerance. The Whitehall study. Lancet 1:1373-1376

7. Tapp RJ, Shaw JE, Zimmet PZ et al (2004) Albuminuria is evident in the early stages of diabetes onset: results from the Australian Diabetes, Obesity, and Lifestyle Study (AusDiab). Am J Kidney Dis 44:792-798. https://doi.org/10.1016/S0272-6386(04)01079-0

8. Chen X, Graham J, Dabbah MA et al (2015) Small nerve fiber quantification in the diagnosis of diabetic sensorimotor polyneuropathy: comparing corneal confocal microscopy with intraepidermal nerve fiber density. Diabetes Care 38:1138-1144. https://doi.org/10.2337/dc14-2422

9. Asghar O, Petropoulos IN, Alam U et al (2014) Corneal confocal microscopy detects neuropathy in subjects with impaired glucose tolerance. Diabetes Care 37:2643-2646. https://doi.org/10.2337/ dc14-0279

10. Serhiyenko VA, Serhiyenko AA (2018) Cardiac autonomic neuropathy: risk factors, diagnosis and treatment. World J Diabetes 9:124. https://doi.org/10.4239/wjd.v9.i1.1 
11. Vinik AI, Ziegler D (2007) Diabetic cardiovascular autonomic neuropathy. Circulation 115:387-397. https://doi.org/10.1161/ CIRCULATIONAHA.106.634949

12. Boulton AJ, Vinik AI, Arezzo JC et al (2005) Diabetic neuropathies: a statement by the American Diabetes Association. Diabetes Care 28:956-962. https://doi.org/10.2337/diacare.28.4.956

13. Zilliox L, Morado M, Kumar P, Fleishmann K, Russell JW (2017) A randomized, blinded, parallel group lifestyle intervention study improves the expiration: inspiration ratio in subjects with diabetic neuropathy. Clin Auton Res 27:340

14. Spallone V, Ziegler D, Freeman R et al (2011) Cardiovascular autonomic neuropathy in diabetes: clinical impact, assessment, diagnosis, and management. Diabetes Metab Res Rev 27:639653. https://doi.org/10.1002/dmrr.1239

15. Tannus LR, Drummond KR, Clemente EL, da Matta Mde F, Gomes MB (2014) Predictors of cardiovascular autonomic neuropathy in patients with type 1 diabetes. Front Endocrinol 5:191

16. Ewing DJ, Campbell IW, Clarke BF (1980) Assessment of cardiovascular effects in diabetic autonomic neuropathy and prognostic implications. Ann Intern Med 92:308-311. https://doi.org/10.7326/ 0003-4819-92-2-308

17. Suarez GA, Clark VM, Norell JE et al (2005) Sudden cardiac death in diabetes mellitus: risk factors in the Rochester diabetic neuropathy study. J Neurol Neurosurg Psychiatry 76:240-245. https://doi. org/10.1136/jnnp.2004.039339

18. Canto JG, Shlipak MG, Rogers WJ et al (2000) Prevalence, clinical characteristics, and mortality among patients with myocardial infarction presenting without chest pain. JAMA 283:3223-3229. https://doi.org/10.1001/jama.283.24.3223

19. Miettinen H, Lehto S, Salomaa V et al (1998) Impact of diabetes on mortality after the first myocardial infarction. The FINMONICA Myocardial Infarction Register Study Group. Diabetes Care 21: 69-75. https://doi.org/10.2337/diacare.21.1.69

20. Katz A, Liberty IF, Porath A, Ovsyshcher I, Prystowsky EN (1999) A simple bedside test of 1-minute heart rate variability during deep breathing as a prognostic index after myocardial infarction. Am Heart J 138:32-38. https://doi.org/10.1016/S0002-8703(99) 70242-5

21. Toyry JP, Niskanen LK, Mantysaari MJ, Lansimies EA, Uusitupa MI (1996) Occurrence, predictors, and clinical significance of autonomic neuropathy in NIDDM. Ten-year follow-up from the diagnosis. Diabetes 45:308-315. https://doi.org/10.2337/diab.45.3.308

22. Schroeder EB, Chambless LE, Liao D et al (2005) Diabetes, glucose, insulin, and heart rate variability: the Atherosclerosis Risk in Communities (ARIC) study. Diabetes Care 28:668-674. https://doi.org/10.2337/diacare.28.3.668

23. Williams SM, Eleftheriadou A, Alam U, Cuthbertson DJ, Wilding JPH (2019) Cardiac autonomic neuropathy in obesity, the metabolic syndrome and prediabetes: a narrative review. Diabetes Ther 10: 1995-2021. https://doi.org/10.1007/s13300-019-00693-0

24. Tesfaye S, Boulton AJ, Dyck PJ et al (2010) Diabetic neuropathies: update on definitions, diagnostic criteria, estimation of severity, and treatments. Diabetes Care 33:2285-2293. https://doi.org/10.2337/ dc10-1303

25. Ziegler D, Voss A, Rathmann W et al (2015) Increased prevalence of cardiac autonomic dysfunction at different degrees of glucose intolerance in the general population: the KORA S4 survey. Diabetologia 58:1118-1128. https://doi.org/10.1007/s00125-0153534-7

26. Ge X, Pan SM, Zeng F, Tang ZH, Wang YW (2014) A simple Chinese risk score model for screening cardiovascular autonomic neuropathy. PLoS One 9:e89623. https://doi.org/10.1371/journal. pone. 0089623

27. Holle R, Happich M, Lowel H, Wichmann HE (2005) KORA-a research platform for population based health research. Gesundheitswesen 67(Suppl 1):S19-S25
28. Kennedy WR, Navarro X, Sutherland DE (1995) Neuropathy profile of diabetic patients in a pancreas transplantation program. Neurology 45:773-780. https://doi.org/10.1212/WNL.45.4.773

29. Balcioglu AS, Akinci S, Cicek D et al (2016) Which is responsible for cardiac autonomic dysfunction in non-diabetic patients with metabolic syndrome: prediabetes or the syndrome itself? Diabetes Metab Syndr 10:S13-S20. https://doi.org/10.1016/j.dsx.2015.09. 001

30. Spallone V (2019) Update on the impact, diagnosis and management of cardiovascular autonomic neuropathy in diabetes: what is defined, what is new, and what is unmet. Diabetes Metab J 43:3-30. https://doi.org/10.4093/dmj.2018.0259

31. World Health Organization (1999) Definition, diagnosis and classification of diabetes mellitus and its complications: report of a WHO consultation. Part 1, diagnosis and classification of diabetes mellitus. World Health Organization, Geneva

32. WHO (2006) Definition and diagnosis of diabetes mellitus and intermediate hyperglycemia: report of a WHO/IDF consultation. World Health Organization, Geneva

33. American Diabetes Association (2014) Diagnosis and classification of diabetes mellitus. Diabetes Care 37(Suppl 1):S81-S90

34. Munn Z, Moola S, Lisy K, Riitano D, Tufanaru C (2015) Methodological guidance for systematic reviews of observational epidemiological studies reporting prevalence and cumulative incidence data. Int J Evid Based Healthc 13:147-153. https://doi.org/ 10.1097/XEB.0000000000000054

35. Higgins JPT, Thompson SG, Deeks JJ, Altman DG (2003) Measuring inconsistency in meta-analyses. BMJ 327:557-560. https://doi.org/10.1136/bmj.327.7414.557

36. Dimova R, Tankova T, Guergueltcheva V et al (2017) Risk factors for autonomic and somatic nerve dysfunction in different stages of glucose tolerance. J Diabetes Complicat 31:537-543. https://doi. org/10.1016/j.jdiacomp.2016.11.002

37. Dinh W, Füth R, Lankisch M et al (2011) Cardiovascular autonomic neuropathy contributes to left ventricular diastolic dysfunction in subjects with type 2 diabetes and impaired glucose tolerance undergoing coronary angiography. Diabet Med 28:311-318. https://doi. org/10.1111/j.1464-5491.2010.03221.x

38. Laitinen T, Lindström J, Eriksson J et al (2011) Cardiovascular autonomic dysfunction is associated with central obesity in persons with impaired glucose tolerance. Diabet Med 28:699-704. https:// doi.org/10.1111/j.1464-5491.2011.03278.x

39. Putz Z, Nemeth N, Istenes I et al (2013) Autonomic dysfunction and circadian blood pressure variations in people with impaired glucose tolerance. Diabet Med 30:358-362. https://doi.org/10. $1111 /$ dme. 12111

40. Zimmerman M, Pourhamidi K, Rolandsson O, Dahlin LB (2018) Autonomic neuropathy-a prospective cohort study of symptoms and $\mathrm{E} / \mathrm{I}$ ratio in normal glucose tolerance, impaired glucose tolerance, and type 2 diabetes. Front Neurol 9:154

41. Dimova R, Tankova T, Kirilov G, Chakarova N, Grozeva G, Dakovska L (2020) Endothelial and autonomic dysfunction at early stages of glucose intolerance and in metabolic syndrome. Horm Metab Res 52:39-48. https://doi.org/10.1055/a-0972-1302

42. Wu J, Yang Y, Lu F, Wu C, Wang R, Chang C (2009) Populationbased study on the prevalence and risk factors of orthostatic hypotension in subjects with pre-diabetes and diabetes. Diabetes Care 32:69-74

43. Balbinot LF, Canani LH, Robinson CC, Achaval M, Zaro MA (2012) Plantar thermography is useful in the early diagnosis of diabetic neuropathy. Clinics (Sao Paulo) 67:1419-1425. https:// doi.org/10.6061/clinics/2012(12)12

44. Callaghan BC, Reynolds EL, Banerjee M et al (2020) The prevalence and determinants of cognitive deficits and traditional diabetic complications in the severely obese. Diabetes Care 43:683-690. https://doi.org/10.2337/dc19-1642 
45. Kamel J, Vogrin S, Knight-Sadler R et al (2014) Combining cutaneous silent periods with quantitative sudomotor axon reflex testing in the assessment of diabetic small fiber neuropathy. Clin Neurophysiol 126(5):1047-1053

46. Rasic-Milutinovic ZR, Milicevic DR, Milovanovic BD, PerunicicPekovic GB, Pencic BD (2010) Do components of metabolic syndrome contribute to cardiac autonomic neuropathy in nondiabetic patients? Saudi Med J 31:650-657

47. Kseneva SI, Borodulina EV, Udut VV (2018) Extension of the metabolic syndrome cluster. Bull Exp Biol Med 164:304-307. https://doi.org/10.1007/s10517-018-3977-1

48. Pappachan JM, Sebastian J, Bino BC et al (2008) Cardiac autonomic neuropathy in diabetes mellitus: prevalence, risk factors and utility of corrected QT interval in the ECG for its diagnosis. Postgrad Med J 84:205-210. https://doi.org/10.1136/pgmj.2007.064048

49. Motataianu A, Maier S, Bajko Z, Voidazan S, Balasa R, Stoian A (2018) Cardiac autonomic neuropathy in type 1 and type 2 diabetes patients. BMC Neurol 18:126

50. Fedorowski A, Stavenow L, Hedblad B, Berglund G, Nilsson PM, Melander O (2010) Orthostatic hypotension predicts all-cause mortality and coronary events in middle-aged individuals (The Malmo Preventive Project). Eur Heart J 31:85-91. https://doi.org/ 10.1093/eurheartj/ehp329

51. The Diabetes Control and Complications Trial Research Group (1998) The effect of intensive diabetes therapy on measures of autonomic nervous system function in the Diabetes Control and Complications Trial (DCCT). Diabetologia 41:416-423. https:// doi.org/10.1007/s001250050924

52. Maser RE, Mitchell BD, Vinik AI, Freeman R (2003) The association between cardiovascular autonomic neuropathy and mortality in individuals with diabetes. A meta-analysis. 26:1895-1901

53. Lonn EM, Rambihar S, Gao P et al (2014) Heart rate is associated with increased risk of major cardiovascular events, cardiovascular and all-cause death in patients with stable chronic cardiovascular disease: an analysis of ONTARGET/TRANSCEND. Clin Res Cardiol 103:149-159. https://doi.org/10.1007/s00392-013-0644-4

54. Wulsin LR, Horn PS, Perry JL, Massaro JM, D Agostino RB (2015) Autonomic imbalance as a predictor of metabolic risks, cardiovascular disease, diabetes, and mortality. J Clin Endocrinol Metab 100:2443-2448. https://doi.org/10.1210/jc.2015-1748

55. Di Carli MF, Tobes MC, Mangner T et al (1997) Effects of cardiac sympathetic innervation on coronary blood flow. N Engl J Med 336:1208-1216. https://doi.org/10.1056/NEJM199704243361703

56. Di Carli MF, Bianco-Batlles D, Landa ME et al (1999) Effects of autonomic neuropathy on coronary blood flow in patients with diabetes mellitus. Circulation 100:813-819. https://doi.org/10. 1161/01.CIR.100.8.813

57. Zobel EH, Hasbak P, Winther SA et al (2019) Cardiac autonomic function is associated with myocardial flow reserve in type 1 diabetes. Diabetes 68(6):1277-1286. https://doi.org/10.2337/db18-1313

58. Pop-Busui R (2012) What do we know and we do not know about cardiovascular autonomic neuropathy in diabetes. J Cardiovasc Transl Res 5:463-478. https://doi.org/10.1007/s12265-012-9367-6

59. Fisher VL, Tahrani AA (2017) Cardiac autonomic neuropathy in patients with diabetes mellitus: current perspectives. Diabetes Metab Syndr Obes 10:419-434

60. Grassi G, Dell Oro R, Facchini A, Quarti Trevano F, Bolla GB, Mancia G (2004) Effect of central and peripheral body fat distribution on sympathetic and baroreflex function in obese normotensives. J Hypertens 22:2363-2369. https://doi.org/10. 1097/00004872-200412000-00019

61. Tesfaye S, Chaturvedi N, Eaton SE et al (2005) Vascular risk factors and diabetic neuropathy. N Engl J Med 352:341-350. https://doi.org/10.1056/NEJMoa032782

62. Wiggin TD, Sullivan KA, Pop-Busui R, Amato A, Sima AAF, Feldman EL (2009) Elevated triglycerides correlate with progression of diabetic neuropathy. Diabetes 58:1634-1640. https://doi. org/10.2337/db08-1771

63. Davis TME, Yeap BB, Davis WA, Bruce DG (2008) Lipidlowering therapy and peripheral sensory neuropathy in type 2 diabetes: the Fremantle Diabetes Study. Diabetologia 51:562 566. https://doi.org/10.1007/s00125-007-0919-2

64. Watkins LL, Surwit RS, Grossman P, Sherwood A (2000) Is there a glycemic threshold for impaired autonomic control? Diabetes Care 23:826-830. https://doi.org/10.2337/diacare.23.6.826

65. Gerstein HC, Santaguida P, Raina P et al (2007) Annual incidence and relative risk of diabetes in people with various categories of dysglycemia: a systematic overview and meta-analysis of prospective studies. Diabetes Res Clin Pract 78:305-312. https://doi.org/ 10.1016/j.diabres.2007.05.004

66. Nathan DM, Davidson MB, DeFronzo RA et al (2007) Impaired fasting glucose and impaired glucose tolerance: implications for care. Diabetes Care 30:753-759

67. Cheng Z, Tseng Y, White MF (2010) Insulin signaling meets mitochondria in metabolism. Trends Endocrinol Metab 21:589-598. https://doi.org/10.1016/j.tem.2010.06.005

68. Vincent AM, Edwards JL, McLean LL et al (2010) Mitochondrial biogenesis and fission in axons in cell culture and animal models of diabetic neuropathy. Acta Neuropathol 120:477-489. https://doi. org/10.1007/s00401-010-0697-7

69. Xu S, Wan Y, Xu M et al (2015) The association between obstructive sleep apnea and metabolic syndrome: a systematic review and meta-analysis. BMC Pulm Med 15:105-105

70. Lombardi C, Pengo MF, Parati G (2019) Obstructive sleep apnea syndrome and autonomic dysfunction. Auton Neurosci 221: 102563. https://doi.org/10.1016/j.autneu.2019.102563

71. Carnethon MR, Prineas RJ, Temprosa M et al (2006) The association among autonomic nervous system function, incident diabetes, and intervention arm in the Diabetes Prevention Program. Diabetes Care 29:914-919. https://doi.org/10.2337/diacare.29.04.06.dc051729

72. Burger AJ, Weinrauch LA, D Elia JA, Aronson D (1999) Effect of glycemic control on heart rate variability in type I diabetic patients with cardiac autonomic neuropathy. Am J Cardiol 84:687-691. https://doi.org/10.1016/S0002-9149(99)00417-8

73. Tahrani AA, Altaf QA, Piya MK, Barnett AH (2017) Peripheral and autonomic neuropathy in South Asians and White Caucasians with type 2 diabetes mellitus: possible explanations for epidemiological differences. J Diabetes Res 2017:1273789. https://doi.org/10.1155/ $2017 / 1273789$

74. Lean MEJ, Leslie WS, Barnes AC et al (2018) Primary care-led weight management for remission of type 2 diabetes (DiRECT): an open-label, cluster-randomised trial. Lancet 391:541-551. https:// doi.org/10.1016/S0140-6736(17)33102-1

Publisher's note Springer Nature remains neutral with regard to jurisdictional claims in published maps and institutional affiliations. 


\section{Affiliations}

\section{Aikaterini Eleftheriadou ${ }^{1}$ - Scott Williams ${ }^{1}$ - Sarah Nevitt ${ }^{2}$. Emily Brown ${ }^{1} \cdot$ Rebecca Roylance $^{3}$ - John P. H. Wilding ${ }^{4}$. Daniel J. Cuthbertson ${ }^{4}$. Uazman Alam ${ }^{5,6,7}$}

1 Department of Cardiovascular \& Metabolic Medicine, Institute of Life Course and Medical Sciences, University of Liverpool, Liverpool, UK

2 Department of Biostatistics, University of Liverpool, Liverpool, UK

3 Edge Hill University Library, Aintree University Hospital NHS Foundation Trust, Liverpool, UK

4 Obesity and Endocrinology Research, Department of Cardiovascular \& Metabolic Medicine, Institute of Life Course and Medical Sciences, University of Liverpool, Liverpool, UK
5 Division of Diabetes, Endocrinology and Gastroenterology, Institute of Human Development, University of Manchester, Manchester, UK

6 Pain Research Institute and Department of Cardiovascular \& Metabolic Medicine, Institute of Life Course and Medical Sciences, University of Liverpool and Aintree University Hospital NHS Foundation Trust, Liverpool, UK

7 Department of Diabetes and Endocrinology, Liverpool University Hospital NHS Trust, Liverpool, UK 